\title{
Expression of Wnt and $\beta$-Catenin in Mouse Tooth Germs and Chick Facial Primordia: A Comparison
}

\author{
Expresión de Wnt y $\beta$-Catenina en Gérmenes de Dientes de Ratón \\ y Primordios Faciales de Polluelos: Una Comparación
}

S. Louryan; N. Vanmuylder; M. Lejong \& M. Duterre

LOURYAN, S.; VANMUYLDER, N.; LEJONG, M. \& DUTERRE, M. Expression of Wnt and $\beta$-Catenin in mouse tooth germs and chick facial primordia: A comparison. Int. J. Morphol., 36(2):569-575, 2018.

SUMMARY: In order to compare Wnt/ $\beta$-catenin expression in mouse and chick facial primordia during development, we performed an immunohistochemical analysis of both protein expressions in E12 to E17 mouse embryos and in E3 and E10 chick embryos. During odontogenesis, from bud to bell stage, both proteins exhibit similar fixation patterns, with epithelial and mesenchymal immunoreactivity, consistant with literature data. Double labelling demonstrates that the same cells express both antigens, even in undifferentiated mesenchyme. The enamel knot, and the ameloblastic and odontoblastic layers are stained at the same manner. In the chick, Wnt and $\beta$-catenin are diffusely present on craniofacial mesenchyme. In both species, premuscular blastemata express Wnt and b-catenin, but Wnt is specifically expressed on the perichondrium and ossification centers, suggesting a role independent from $\beta$-catenin pathway.

KEY WORDS: Mouse; Chick; Embryo; Wnt; b-catenin; Tooth.

INTRODUCTION

The proteins Wnt, whose the name is derived from the drosophila gene wingless and int-1, a proto- oncogene known in the mouse, constitute a broad family implied in the morphogenesis of various systems, like the nervous system, the head, the limb buds. It acts of glycoproteins, and their transduction passes generally through b-catenin expression, in the so-called "canonical way" (Darribère, 2012). Wnt's , in Wnt/ $\beta$-catenin pathway, initiate ectodermal appendages development (Logan \& Nusse, 2004).

The expression of various Wnt proteins was studied during odontogenesis (Sarkar \& Sharpe, 1999), and also during general facial development (Geetha-Loganathan et al., 2009), while the $\mathrm{Wnt} / \beta$-catenin way was studied on tooth germs (Liu et al., 2008; Lo Muzio et al., 2009; Fujimori et al., 2010; Wang et al., 2014). Wnt's express in chick head development (Geetha-Loganathan et al.; Kawakami et al. 2014), but no close correlation was made between Wnt and $\beta$-catenin expression in birds.

The purpose of this work is to compare $\beta$-catenin and Wnt expression during mouse odontogenesis using separate and double staining, and correlate these results with similar data obtained in the facial primordia of chick embryos.

\section{MATERIAL AND METHOD}

In order to be able to examine the various stages of odontogenesis, mouse embryos from E12 to E17 (6 stages) were taken, the day of vaginal plug being considered as day 0 . Pregnant mothers were killed by $\mathrm{CO}_{2}$ exposure, the embryos were fixed using the Serra's fixative medium. After dehydration in alcohol and paraffin embedding, $5 \mu \mathrm{m}$ coronal sections were placed on slides and stored until further processing. For each case, serial alternating sections were prepared. The tissue sections, which were mounted on slides, were deparaffined and rehydrated through a graded series of alcohol and water. To permeabilize the cellular membranes, the slides were placed in citrate buffer and irradiated in a microwave at $650 \mathrm{~W}$ for $2 \mathrm{~min}$. After progressive cooling in citrate and washing in phosphate buffered saline (PBS) containing $0.1 \%$ Triton X100® to further permeabilize the cytoplasmic membrane, the slides were incubated in normal blocking reagent (Millipore, Temecula, Ca, USA) for 120 min to block non-specific binding sites. This reagent was then removed, and the slides were incubated overnight in a humidified chamber with rabbit anti-Wnt polyclonal antibody (Biorbyt, Cambridge, UK) $1 \%$ in PBS or Human/Mouse/Rat catenin antibody polyclonal goat IgG (R\&D systems Biotechne, Minneapolis, Mi, USA). Slides were washed in PBS and Triton X-100®, 
and endogenous peroxidase was blocked by incubation in methanol containing $0.3 \%$ hydrogen peroxide. Then, the slides were incubated with goat antirabbit IgG (Millipore, Temecula or GAR, Hercules, Ca) for $30 \mathrm{~min}$. After washing with PBS, the slides were incubated with streptavidin HRP (Millipore, Temecula) for $30 \mathrm{~min}$. After PBS washing, they were incubated with a peroxidase substrate solution containing diaminobenzidine (Dako, Carpinteria, CA, USA) for $4 \mathrm{~min}$. The procedure of revelation of $\beta$-catenin was similar; the primary antibody was a rabbit polyclonal (EHC Millipore) diluted at 1/100. Finally, the slides were rinsed in tap water, dehydrated through a graded alcohol series, mounted in DPX and examined under light microscopy. The Wnt antibody was derived from the Wnt-1 human protein and the immunogenic sequence (UniProtKB-P04628) exhibits homologies with other Wnt proteins (100\% for Wnt4 isoform X2, Wnt-4 precursor, Wnt-4 isoform X1). For double staining in fluorescence, the slices were incubated overnight with goat polyclonal anti $\beta$-catenin C18 (Santa Cruz, Dallas, TX, USA) diluted at 1/100; the same anti-Wnt antibody, normal goat serum (1/100) and normal rabbit serum 1/100). The secondary antibodies were for Wnt the MAR Alexa 594 (Thermo-Fisher, Waltham, MA, USA) and for b-catenin DAGAlexa 488 (Thermo-Fisher) 1/200. E4 chick embryos were stained following the same methodology.

In order to compare Wnt and $\beta$-catenin expression in mouse and chick embryos, chick embryos of E3 and E10 were removed from eggs incubated at $37^{\circ} \mathrm{C}$, sliced and stained following the same procedures as described for mouse embryos.

Negative controls were performed by missing of primary or secondary antibodies, and by exposition to rabbit and/or goat serum. Corresponding sections displayed no significant staining.

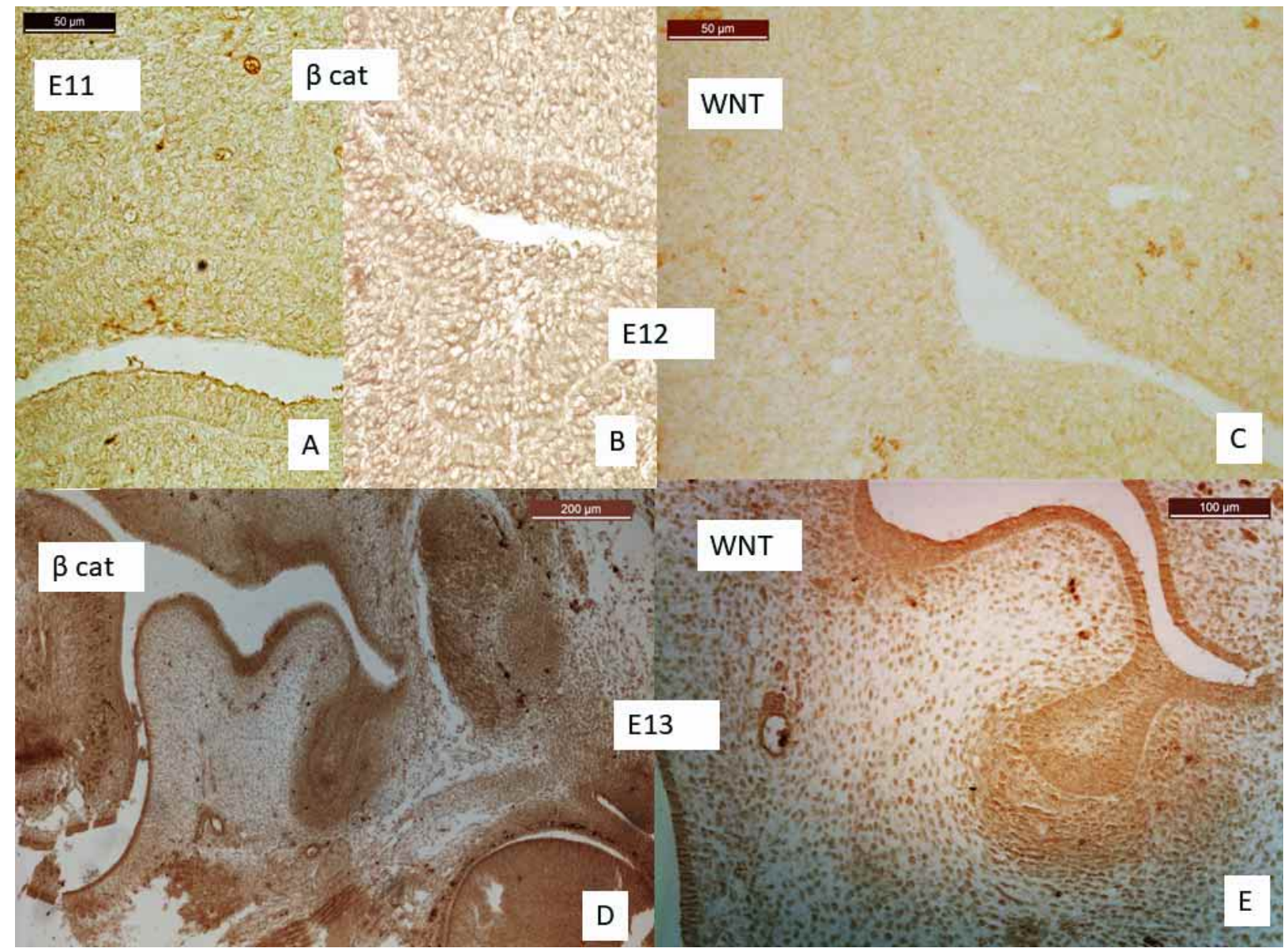

Fig. 1. A. E11 mouse embryo. Very weak immunoreactivity of $\beta$-catenin in the dental epithelium, as well as in surrounding mesenchyme. B. E12 mouse embryo, same observation. C. E12 mouse embryo: Wnt exhibits also a very weak immunoreactivity in the molar dental epithelium and in mesenchyme. D: E13 mouse embryo: the $\beta$-catenin staining becomes more significative in dental mesenchyme and enamel epithelium. The immunoreactivity in cytoplasmic as well as nuclear. E13 mouse embryos: Same observations. Staining remains present in the facial mesenchyme. 


\section{RESULTS}

At early stages (Fig. 1) a weak cytoplasmic expression of $\beta$-catenin is present in the dental lamina and the oral epithelium, as well as in the mesenchyme. Wnt appears in the same locations as $\beta$-catenin, with a nuclear and cytoplasmic expression.

At the dental bud stage (E 12-13), b-catenin and Wnt present a similar location in oral epithelium, enamel epithelium and dental mesenchyme. Both proteins were visible in the surrounding mesenchyme, but with less intense immunoreactivity than in dental primordia.

At the dental cup stage (E 14-17) (Fig. 2 to 5), the dental epithelium continues to express Wnt and b-catenin. But mesenchymal fixation becomes progressively more intense in the deep part of the mesenchyme corresponding to the future odontoblastic layer (Figs. 3, 4 and 7).
The epithelial antibodies fixation is more intense in two areas: in the enamel knot and in the peripheral parts of inner enamel epithelium. The facial mesenchyme remained weakly positive for both antibodies. Their fixation in the enamel knot is relatively moderate at days 15 and 16 but becomes more intense at E17.

The premuscular primordia appear more positive than the undifferentiated mesenchyme.

Double staining demonstrates that the same cell populations of the tooth bud express both Wnt and $\beta$-catenin (Figs. 4 and 5). However, cells devoted to form the follicular sac seem to express more $\beta$-catenin than Wnt.

In the chick embryo (Figs. 6 and 7), a diffuse staining of $\beta$-catenin and Wnt is observed, with more intense fixation on oral epithelium and premuscular blastemata. Wnt seems to be specifically expressed in perichondrium and ossification areas, with no counterpart of $\beta$-catenin (Figs. 5 and 7).

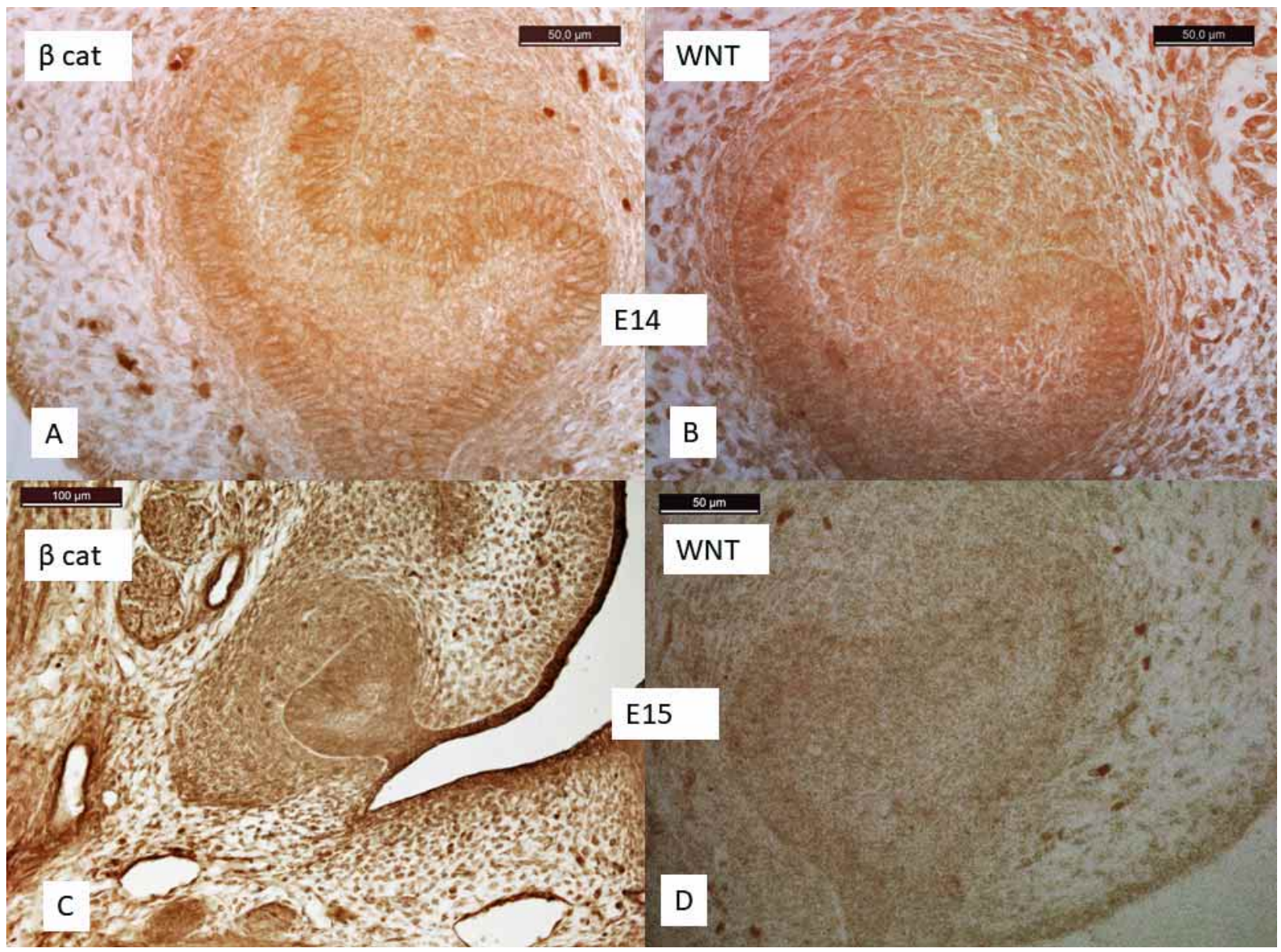

Fig. 2. A. E14 mouse embryo. $\beta$-catenin immunoreactivity in the dental lamina, the dental mesenchyme and the enamel knot. Staining predominates in the cytoplasm but in present in several nuclei. The staining is not homogenous, and some cells seem to be more stained than others. C and D: similar features in E15 mouse embryos (C: $\beta$-catenin, D: Wnt). 


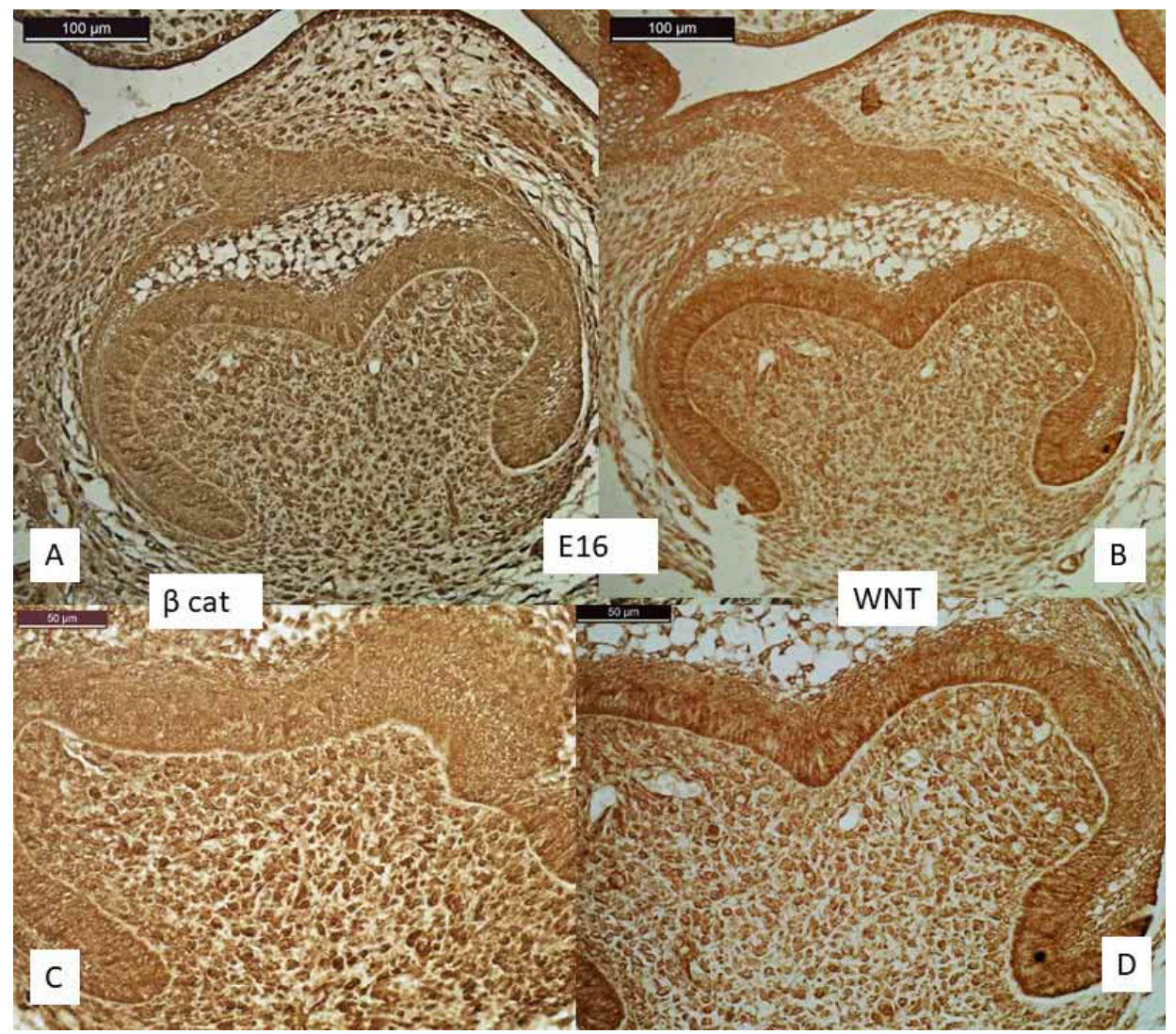

Fig. 3. E16 mouse embryo, molar bell, $\beta$-catenin (A, C) and Wnt (B, D). Same patterns of fixation, both nuclear and cytoplasmic, including some differences from cell to cell. In the dental mesenchyme, odontoblastic layer becomes well stained and recognizable.

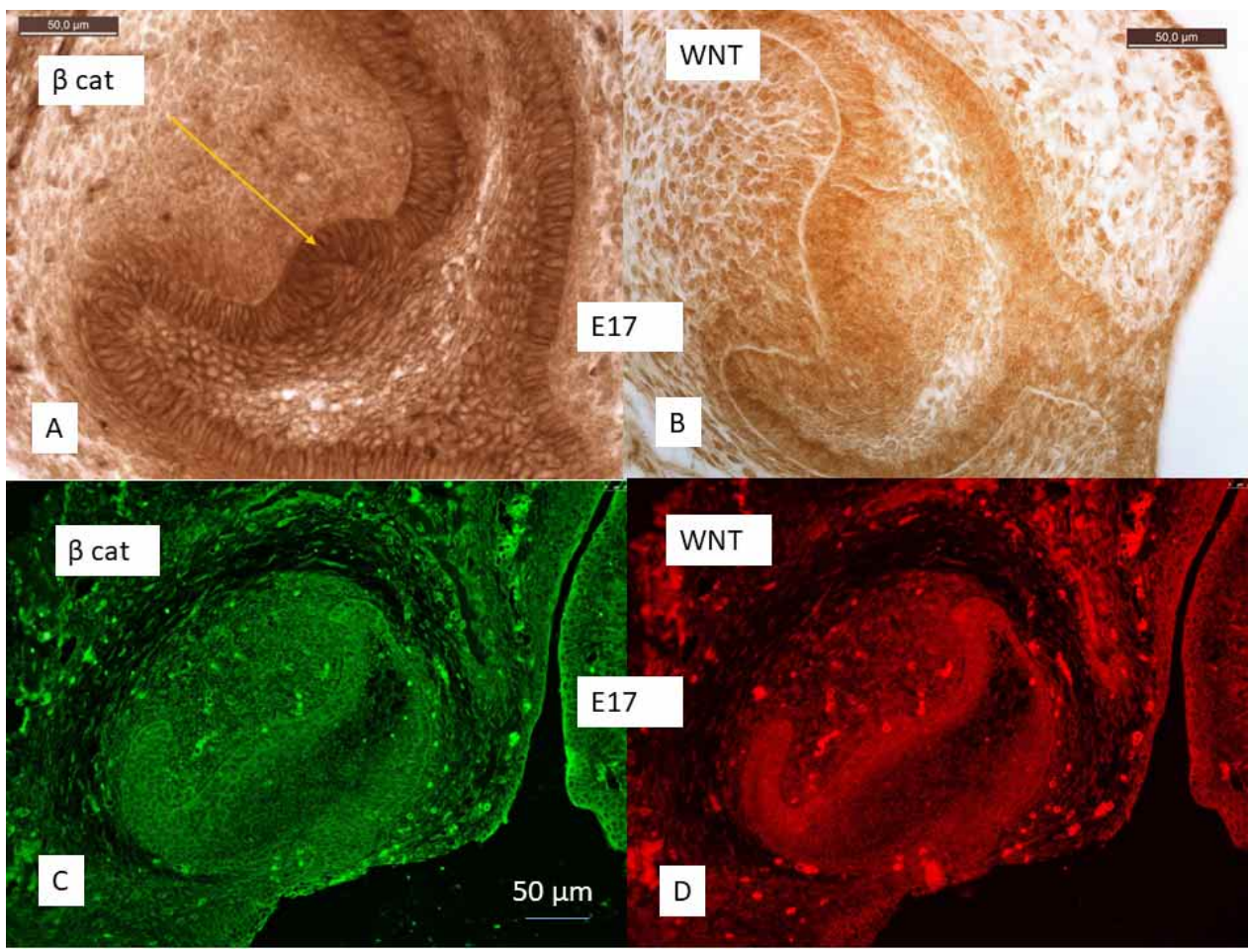

572
Fig. 4. E17 mouse embryo. $\beta$ catenin (DAB-peroxydase, A, immunofluorescence, $C$ ) and Wnt (DAB-peroxydase, B and immunofluorescence, D). At this stage, $\beta$-catenin is largely expressed in the cytoplasm, but Wnt keeps a nuclear localization. $\beta$-catenin is strongly expressed on the enamel knot (arrow), and in the stellate reticulum(A). 


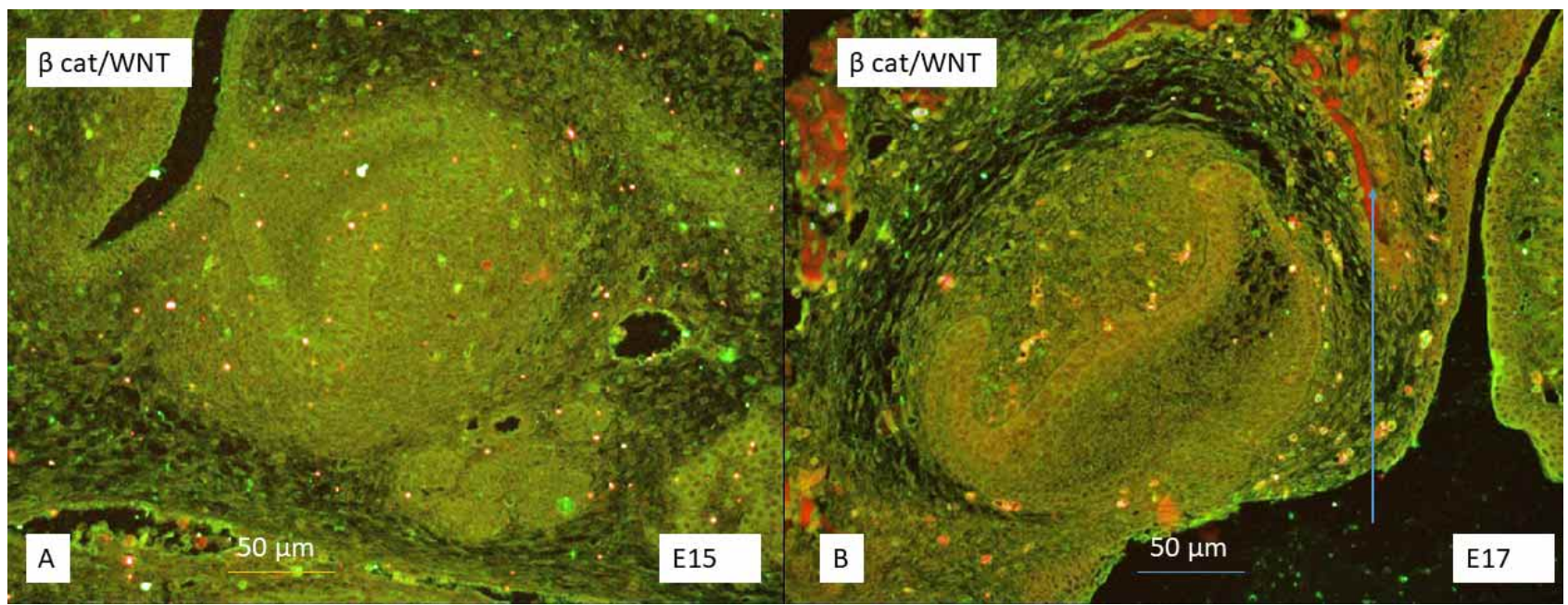

Fig. 5. E17 mouse embryo. Double staining of $\beta$-catenin and Wnt1 showing that a lot of cells of each population express both proteins. Furthermore, we can observe a specific Wnt immunoreactivity in intramembranous ossification areas of the maxillary bone (arrow), and we confirm that $\beta$-catenin expression is predominant in the cytoplasmic area.

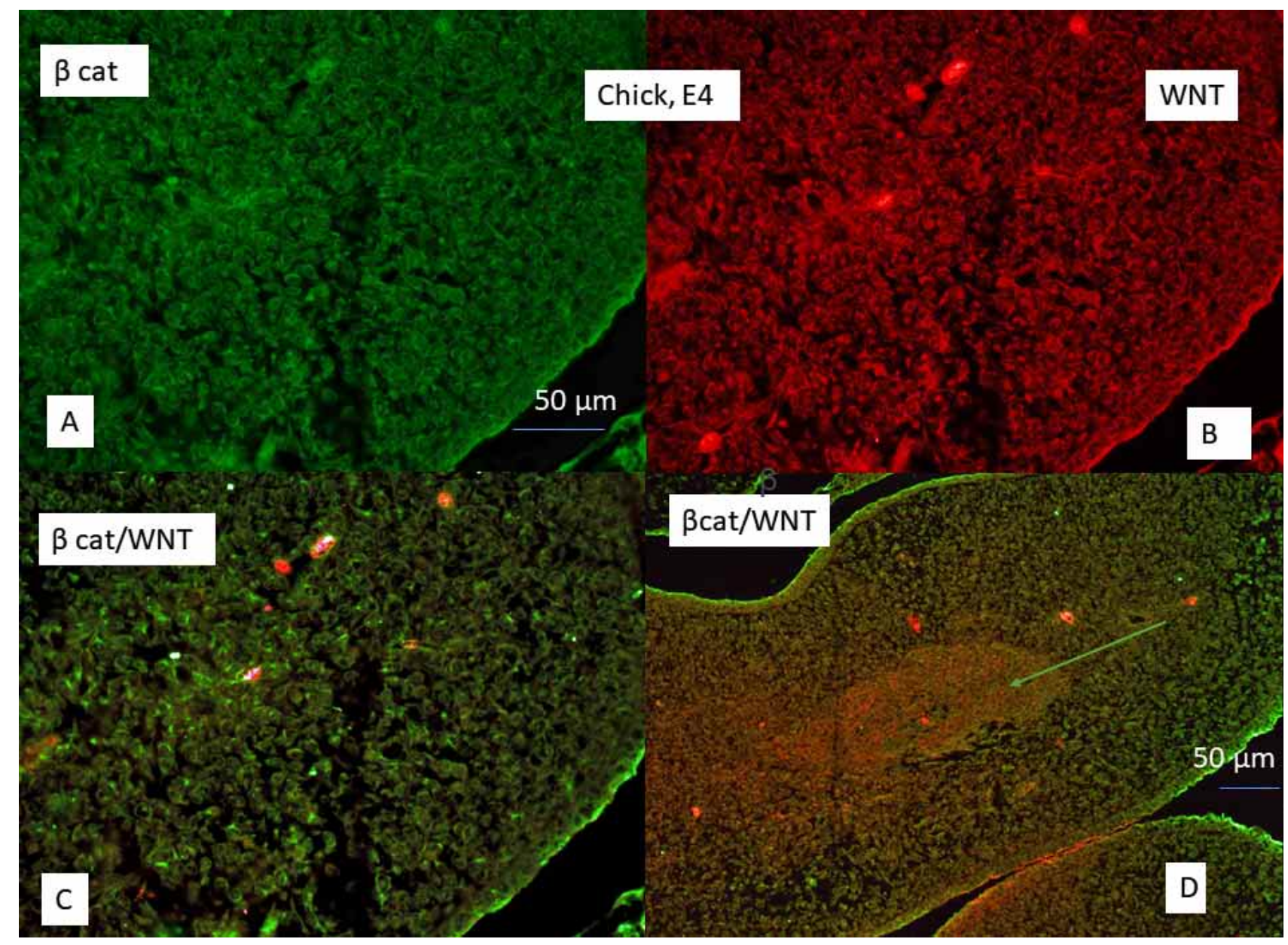

Fig. 6. E3 chick embryo. Immunofluorescence of b-catenin (A) et Wnt expression (B) in the mandibular process. C and D: double staining of both fixations. We observe a very diffuse immunoreactivity in the mesenchyme. Wnt express strongly on the first branchial arch premuscular blastema (arrow). 


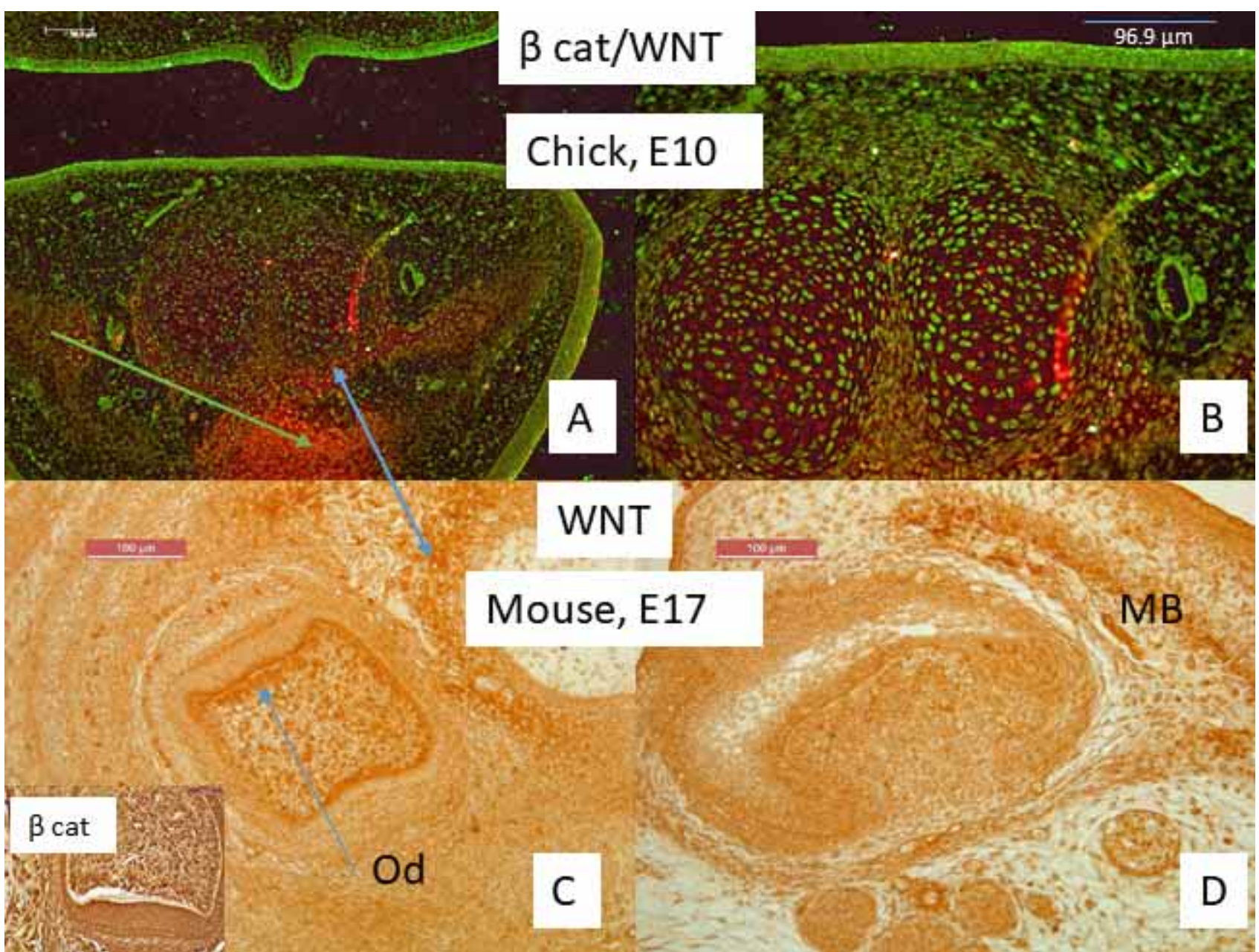

Fig. 7. Comparison of E10 chick embryo (immunofluorescence) (A-B) and E17 mouse embryo (DAB-peroxydase)(C-D). Low (A) and high (B) magnification of double staining of $\beta$-catenin and Wnt1 in the chick mandibular bud, in the area of fusion of both Meckel's cartilage. Nuclear immunoreactivity of Wnt1 is very strong in the perichondrium (double arrow), and both cytoplasmic and nuclear fixations of the antibodies appear in the premuscular mass (arrow) inferior to the cartilages. In the mouse embryo, the intramembranous bone (MB) is highly stained, and we can compare similar staining of perichondria in chick and mouse (double arrow). The odontoblastic layer of incisor teeth displays similar pattern of Wnt and $\beta$-catenin (C).

\section{DISCUSSION}

$\beta$-catenin is recognized as essential for tooth development, particularly in the incisors, where it controls the expression of Bmp4, which constitutes a key factor for tooth development (Fujimori et al.).

The "canonical" way of activation of b-catenin postulates the intervention of the Wnt family genes, which recognize a receptor complex containing a member of the family Frizzled and a LDL receptor protein. The fixation of Wnt causes a cytoplasmic accumulation of $\beta$-catenin. A part of this one penetrates the nucleus and acts like a transcription factor. Activation of the Wnt/ $\beta$-catenin cascade leads to ectopic dental invaginations, and permits, in some conditions, to reactivate tooth development in birds (Harris et al., 2006). Knock-out of Wnt1 causes deficiencies in neural crest derivatives and neural tube (Logan \& Nusse).

$\beta$-catenin is present during all stages of odontogenesis (Liu et al.; Lo Muzio et al.), in both enamel epithelium and dental mesenchyme. $\beta$-catenin is required to initiate enamel knot development, and induces expression of Lef1 and Fgf3 in the tooth germ (Chen et al., 2009). This could explain the 
high level of expression of Wnt and b-catenin we observed, particularly in the enamel knot.

Wnt1 is known to be expressed, during brain development, in the craniofacial mesenchyme of mouse embryo (Gavin et al., 1990), but seems to be absent on whole mounts in chick embryo facial buds (Geetha-Loganathan et al.). We demonstrated here that a global Wnt immunoreactivity is present in the facial mesenchyme of young chick embryos. Wnt immunoreactivity is consistent with the fact that inhibition of the $\mathrm{Wnt} / \beta$-catenin pathway by Dikkopf-1 is known to affect the facial development in the chick embryo (Kawakami et al.). Wnt fixation occurs generally in the same cells than b-catenin, but is observed more intensively in muscular blastemata, perichondrium and ossification areas. These features are consistent with the fact that Wnt signaling is involved in cartilage (Usami et al., 2016) and muscle development (von Maltzahn et al., 2012).

The pattern of expression of various Wnt genes during odontogenesis was analyzed in mouse embryo (Sarkar \& Sharpe; Liu et al.). Wnt genes expression is mainly considered as epithelial (with extension in the stellar reticulum), except for Wnt5A whose expression occurs in mesenchyme. The fact that our anti Wnt antibody recognizes all Wnt proteins explains its fixation on both epithelial and mesenchymal cells and the high correlation between $\mathrm{Wnt}$ and $\beta$-catenin immunoreactivity, associated in the canonic pathway.

LOURYAN, S.; VANMUYLDER, N.; LEJONG, M. \& DUTERRE, M. Expresión de Wnt y $\beta$-catenina en gérmenes de dientes de ratón y primordios faciales de polluelos: Una comparación. Int. J. Morphol., 36(2):569-575, 2018.

RESUMEN: Para comparar la expresión de Wnt / $\beta$ catenina en primordios faciales de ratón y de polluelo durante el desarrollo, se realizó un análisis inmunohistoquímico de ambas expresiones de proteína en embriones de ratón E17 a E17 y en embriones de pollo E3 y E10. Durante la odontogénesis, desde el brote hasta la etapa de la campana, ambas proteínas exhiben un patrón de fijación similar, con inmunorreactividad epitelial y mesenquimal, consistente con los datos de la literatura. El doble etiquetado demuestra que las mismas células expresan ambos antígenos, incluso en el mesénquima no diferenciado. El nudo del esmalte y las capas ameloblástica y odontoblástica se tiñen de la misma manera. En el pollo, Wnt y $\beta$-catenina están difusamente presentes en el mesénquima craneofacial. En ambas especies, los blastemas premusculares expresan Wnt y $\beta$-catenina, pero Wnt se expresa específicamente en el pericondrio y los centros de osificación, lo que sugiere un papel independiente de la ruta de la $\beta$ catenina.

PALABRAS CLAVE: Ratón; Polluelo ; Embrión; Wnt; $\beta$-catenina; Diente.

\section{REFERENCES}

Chen, J.; Lan, Y.; Baek, J. A.; Gao, Y. \& Jiang, R. Wnt/beta-catenin signaling plays an essential role in activation of odontogenic mesenchyme during early tooth development. Dev. Biol., 334(1):174-85, 2009.

Darribère, Th. Introduction à la Biologie du Développement. Paris, Belin, 2012.

Fujimori, S.; Novak, H.; Weissenböck, M.; Jussila, M.; Gonçalves, A.; Zeller, R.; Galloway, J.; Thesleff, I. \& Hartmann, C. Wnt/b-catenin signaling in the dental mesenchyme regulates incisor development by regulating Bmp4. Dev. Biol., 348(1):97-106, 2010.

Gavin, B. J.; McMahon, J. A. \& McMahon, A. P. Expression of multiple novel Wnt-1/int-1-related genes during fetal and adult mouse development. Genes Dev., 4(12 B):2319-32, 1990.

Geetha-Loganathan, P; Nimmagadda, S.; Antoni, L.; Fu, K; Whiting, C. J.; Francis-West, P. \& Richman, J. M. Expression of WNT signalling pathway genes during chicken craniofacial development. Dev. Dyn., 238(5):1150-65, 2009.

Harris, M. P.; Hasso, S. M.; Ferguson, M. W. \& Fallon, J. F. The development of archosaurian first-generation teeth in a chicken mutant. Curr. Biol., 16(4):371-7, 2006.

Kawakami, M.; Okuda, H.; Tatsumi, K.; Kirita, T. \& Wanaka, A. Inhibition of Wnt/ $\beta$-catenin pathway by Dickkopf-1 [corrected] affects midfacial morphogenesis in chick embryo. J. Biosci. Bioeng., 117(6):664-9, 2014.

Liu, F.; Chu, E. Y.; Watt, B.; Zhang, Y.; Gallant, N. M.; Andl, T.; Yang, S. H.; Lu, M. M.; Piccolo, S.; Schmidt-Ullrich, R.; Taketo, M. M.; Morrisey, E. E.; Atit, R; Dlugosz, A. A. \& Millar, S. E. Wnt/beta-catenin signaling directs multiple stages of tooth morphogenesis. Dev. Biol., 313(1):210-4, 2008.

Lo Muzio, L.; Lo Russo, L.; Pannone, G.; Santoro, A.; Leonardi, R.; Serpico, R.; Gasparoni, A. \& Bufo, P. Expression of beta-catenin in human tooth germ. Anal. Quant. Cytol. Histol., 31(5):324-31, 2009.

Logan, C. Y. \& Nusse, R. The Wnt signaling pathway in development and disease. Annu. Rev. Cell Dev. Biol, 20:781-810, 2004.

Sarkar, L. \& Sharpe, P. T. Expression of Wnt signalling pathway genes during tooth development. Mech. Dev., 85(1-2):197-200, 1999.

Usami, Y.; Gunawardena, A. T.; Iwamoto, M. \& Enomoto-Iwamoto, M. Wnt signaling in cartilage development and diseases: lessons from animal studies. Lab. Invest., 96(2):186-96, 2016.

von Maltzahn, J.; Chang, N. C.; Bentzinger, C. F. \& Rudnicki, M. A. Wnt signaling in myogenesis. Trends Cell Biol., 22(11):602-9, 2012.

Wang, B.; Li, H.; Liu, Y.; Lin, X.; Lin, Y.; Wang, Y.; Hu, X. \& Zhang, Y. Expression patterns of WNT/b-CATENIN signaling molecules during human tooth development. J. Mol. Histol., 45(5):487-96, 2014.

Corresponding author:

Prof. Stéphane Louryan

Membre de l'Académie Royale de Médecine de Belgique

Directeur, Laboratoire d'Anatomie, Biomécanique et

Organogenèse

Université Libre de Bruxelles, Faculté de Médecine

Route de Lennik, 808, CP 619

B 1070 Bruxelles - BELGIQUE

Email: slouryan@ulb.ac.be 